\title{
Avaliação comparativa de quatro medicamentos à base de ivermectina no ganho de peso de bovinos de corte
}

Yasmin Gonçalves Pereira[a]", Rodrigo César Medeiros da Silva ${ }^{[b]}$, Fabiana Batalha Knackfuss ${ }^{[c]}$, Marta Valéria Rangel da Matta ${ }^{[c]}$, Marcelo Alves Herdy ${ }^{[c]}$

\author{
[a] Jotagro Alimentos, Itaocara, RJ, Brasil

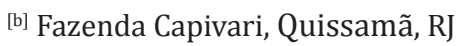 \\ [c] Universidade do Grande Rio (UNIGRANRIO), Duque de Caxias, RJ, Brasil
}

*Autor correspondente

e-mail: yasmin.pereira01@yahoo.com.br

\section{Resumo}

Nos últimos anos tem-se verificado um rápido desenvolvimento de resistência a anti-helmínticos e a limitada eficiência desse método para a supressão das endoparasitoses em ruminantes, o que causa elevadas perdas econômicas e incentiva diversas pesquisas com métodos alternativos de controle parasitário. Um dos principais desafios das propriedades de gado de corte nos dias atuais é a escolha do melhor antiparasitário, já que existem no mercado inúmeras opções com preços bastante variáveis. 0 objetivo deste estudo foi avaliar o efeito de quatro diferentes produtos anti-helmínticos à base de ivermectina sobre o ganho de peso de um rebanho da raça Nelore pertencente à fazenda Capivari, localizada no município de Quissamã, na região norte fluminense do estado do Rio de Janeiro. Foram pesados mensalmente durante cinco meses machos inteiros da raça Nelore com 20 meses de idade, sendo 43 pertencentes ao grupo controle (GC), que não recebeu nenhum anti-helmintico, 34 ao grupo A (ivermectina a 4\%), 31 ao Grupo B (ivermectina a 3,15\%), 31 ao C (ivermectina a 3,5\%, associada a abamectina 1,25\%) e 33 ao D (ivermectina a 3,5\%). As estimativas dos coeficientes de correlação de Pearson entre todas as pesagens dentro dos grupos avaliados foram altas e significativas, variando de 0,71 a 0,98 , demonstrando uma tendência de aumento de peso nos tratamentos entre as diferentes pesagens. As médias de ganho de peso e desvio-padrão para os grupos GC, A, B, C e D foram respectivamente: $570 \mathrm{~g} / \mathrm{dia}( \pm 250), 560 \mathrm{~g} / \mathrm{dia}( \pm 270), 610 \mathrm{~g} / \mathrm{dia}( \pm 360), 610 \mathrm{~g} / \mathrm{dia}$ $( \pm 410)$ e $650 \mathrm{~g} / \mathrm{dia}( \pm 310)$. Não foi verificada diferença estatística significativa $(\mathrm{F}=0,048, \mathrm{P}=0,99)$ pela ANOVA entre os ganhos de peso nos grupos estudados, demonstrando que os diferentes anti-helmínticos apresentaram o mesmo resultado para esta variável, o que pode estar associado tanto a uma baixa carga parasitária devido a resíduos da vermifugação realizada 150 dias antes do início do experimento, quanto 
a uma possível resistência parasitária. Visto que os diferentes produtos testados apresentam uma grande diferença de preço no mercado ,e em virtude de não terem apresentado diferença estatística significativa no ganho de peso, o presente estudo se mostra relevante com relação à economia que pode ser gerada para o criador na escolha do produto mais adequado ao seu rebanho. 